\title{
Toll-Like Receptor-4 Gene (Asp299Gly) polymorphism in allergic conjunctivitis
}

The Egyptian Journal of Immunology

Volume 29 (1), 2022: 01-12.

www.Ejimmunology.org

\author{
Shereen A. Baioumy ${ }^{1}$, Sara I. Taha ${ }^{2}$, Dina E. Sallam ${ }^{3}$, \\ Ahmed I. A. Alashry ${ }^{4}$, Shaimaa H. Fouad ${ }^{5}$ and \\ Mohammed A. Hegab ${ }^{6}$
}

\author{
${ }^{1}$ Department of Microbiology \& Immunology, Faculty of \\ Medicine, Zagazig University, Zagazig, Egypt. \\ ${ }^{2}$ Department of Clinical Pathology, Faculty of Medicine, \\ Ain-Shams University, Cairo, Egypt. \\ ${ }^{3}$ Department of Pediatrics \& Pediatric Nephrology, \\ Faculty of Medicine, Ain-Shams University, Cairo, Egypt. \\ ${ }^{4}$ Department of Ophthalmology, Military Medical \\ Academy, Cairo, Egypt.
}

${ }^{5}$ Department of Internal Medicine, Allergy \& Clinical Immunology, Ain Shams University, Cairo, Egypt

${ }^{6}$ Department of Ophthalmology, Faculty of Medicine, Zagazig University, Zagazig, Egypt.

Corresponding author: Shereen A. Baioumy, Department of Microbiology \& Immunology, Faculty of Medicine, Zagazig University, Zagazig, Egypt.

Email: drshereenatef@yahoo.com.

\begin{abstract}
Allergic conjunctivitis (AC) is an allergic reaction that causes inflammation of the conjunctiva. Toll-like receptors (TLRs) are essential innate immune receptors that contribute to developing various allergic diseases. This case-control study aims to determine the correlation between TLR-4 gene (Asp299Gly) polymorphism and AC incidence and severity. The study included 70 AC patients and 70 non-allergic controls. All included subjects were subjected to a skin prick test, total immunoglobulin $E$ (IgE) measurement, and TLR-4 gene (Asp299Gly) polymorphism detection by PCR restriction fragment length polymorphism (PCR-RFLP) technique. AC patients had significantly higher total IgE levels than controls $(P \leq 0.001)$. The frequency of the wild-type $A A$ and heterozygous $A G$ genotype were significantly lower in AC patients compared to controls (60 \% vs. $80 \%$ and $8.6 \%$ vs. $12.9 \%$, respectively). In contrast, the homozygous mutant GG genotype was significantly more prevalent among AC patients than controls (31.4\% vs. $7.1 \%)$. Furthermore, the wild AA genotype was strongly associated with mild disease (68.2\%); nonetheless, the homozygous mutant GG genotype was linked to severe disease (53.8\%). The heterozygous AG genotype was only found in moderate AC patients (17.1\%). AC patients with the mutant $G$ allele may be more likely to have a severe course of $A C$.
\end{abstract}

Keywords: Allergic; Asp299Gly; Conjunctivitis; Polymorphism; Toll like receptor

Date received: 24 September 2021; accepted: 30 November 2021

\section{Introduction}

Ocular allergy (OA) is a hypersensitivity disorder identified with a clinical history of signs and symptoms and in vivo and in vitro allergen testing. ${ }^{1}$ Allergic conjunctivitis $(\mathrm{AC})$ is the most common $\mathrm{OA}$, which is usually mediated by the immunoglobulin (Ig)-E. It significantly impacts patient quality of life due to its frequent association with other allergic disorders, particularly rhinitis (rhino-conjunctivitis). ${ }^{2} \mathrm{AC}$ is divided into two types: seasonal (SAC) and perennial (PAC); with the former being the more frequent, they differ in frequency of 
symptoms depending on the sensitizing allergen, affecting $15-20 \%$ of the general population. ${ }^{3,4}$ Seasonal allergens such as tree or grass pollens induce seasonal symptoms, while indoor allergens like house dust mites, mold spores, cockroaches, and rats cause perennial symptoms. $^{5} \quad \mathrm{OA}$ intervention requires collaboration between ophthalmologists, dermatologists, pediatricians, and immunologists. 6 According to Bernstein et al., 2008, skin prick tests are used to analyze a panel of common aeroallergens often encountered (house dust mites, mixed grass, mixed pollens, molds, cockroaches, cotton, wool, pigeon feathers, cat hair). ${ }^{7}$

Toll-like receptors (TLRs) in humans are pattern recognition receptors that contribute to the early pathogen detection and subsequent initiation of the innate immune response. They also can influence the cellular immune response that changes the disease vulnerability. ${ }^{8}$ TLRsinduced activation of the immune system results in the production of proinflammatory cytokines like tumor necrosis factor-alpha, interleukin (IL)-1, and IL-6, as well as regulatory cytokines (IL-12 and IL-18), leading to T-helper (Th)1 differentiation and reduction in Th2 response. ${ }^{9}$ TLR-4 is expressed in both the epithelium and the stroma of the conjunctiva, and its activation results in cytokine production. ${ }^{10}$ Bonini et al., 2005, compared the expression of TLR2, 4, 9 in conjunctival specimens of AC patients and patients with cataract. The study revealed that the expression of TLR-4 was significantly increased in patients with $A C$ and was localized in eosinophils, CD4+ve T-cells, and mast cells. ${ }^{11}$

TLRs were investigated to find links between their variations and the incidence of allergic diseases. $^{12}$ TLR genes demonstrate many differences in human subjects, with ten different TLRs identified in humans may be involved in the development of allergic diseases. $^{13}$ However, the impact of these genetic differences on immunological responses or the risk of immune-mediated illnesses remains under investigation. ${ }^{14}$

Single nucleotide polymorphisms (SNPs), the most common alterations in the human genome, have been widely used to detect their association with disease susceptibility in various allergic disorders. ${ }^{15}$ Previous studies have not found conclusive evidence for an association between genetic variations of TLR-4 and AR. ${ }^{16-18}$ However, in 2000, Arbour et al., reported that the TLR-4 (Asp299Gly) SNP is linked to airway hypo-responsiveness in humans. ${ }^{19}$ In addition, numerous studies have found a link between the TLR-4 (Asp299Gly) SNP and asthma, particularly atopic asthma. ${ }^{20-22}$ To the best of our knowledge, studies to assess the genetic variations of TLR-4 and AC are lacking. Consequently, the current study aims to assess the role of TLR-4 (Asp299Gly) SNP in AC susceptibility and severity.

\section{Subjects and Methods}

\section{Study design and subjects}

In this case-control study, patients were recruited from Zagazig and Ain Shams Universities hospitals in the period between January and March 2021.

Since no previous studies have been conducted to assess the genetic variations of TLR-4 and AC, we depended on data of Böttcher et al., 2004, who studied the TLR4 (Asp299Gly) SNPs in the presence of asthma and allergic rhino-conjunctivitis (ARC) in children. ${ }^{37}$ We assumed that the percentage of AA genotypes in the case group versus the control group was $81 \%$ versus $97 \%$, with a $95 \%$ confidence and a power level of $80 \%$. In addition, the total sample size calculated by Open Epi was 140, 70 in each group.

The control group included 70 non-allergic subjects, and the AC group included 70 patients with SAC or PAC without any corneal involvement as detected by slit-lamp microscopic examination. AC patients had a positive skin prick test for common allergens with a typical response to topical therapy (antihistamines or mast cell stabilizers). Patients with eczema, a history of infectious conjunctivitis (e.g., viral) in the past few months, non-allergic causes of conjunctivitis (e.g., superior limbic kerato-conjunctivitis, drug toxicity conjunctivitis, and cicatricial conjunctivitis) were excluded from the study. Contact lens wearers were also excluded. 
All participants were subjected to the following procedures: 1) History taking, which included age, gender, residence, occupation, and family history of atopy. 2) Complete ophthalmological examination to determine AC severity, according to the 2020 Allergic Rhinitis and its Impact on Asthma (ARIA) guidelines ${ }^{23}$. 3) Skin prick testing (SPT): A week prior to the skin testing, subjects were urged to stop taking antihistamines. The positive control was histamine dihydrochloride $(10 \mathrm{mg} / \mathrm{ml})$, while the negative control was saline. The diameter of the largest developed wheal was measured and termed positive if it was $\geq 3 \mathrm{~mm} .{ }^{24}$ One drop $(0.05 \mathrm{~mL})$ of each allergen extract was pricked into the skin. Aqueous allergen extracts (1:100 wt./vol) for skin testing were manufactured locally in the Allergy and Immunology Unit, Faculty of Medicine, Ain Shams University, according to guidelines developed by the American Academy of Allergy, Asthma \& Immunology (AAAAI). ${ }^{25}$

\section{Blood sample collection}

From each participant, $4 \mathrm{~mL}$ of blood was collected via venipuncture under strict aseptic conditions using two vacutainer tubes: an EDTAcontaining tube that was stored at $-80^{\circ} \mathrm{C}$ until further processing for $P C R$ restriction fragment length polymorphism (PCR-RFLP) of the TLR-4 gene, and a plain tube for serum separation by centrifugation at $1000 \times g$ for 15 minutes. Sera were stored at $-20^{\circ} \mathrm{C}$ until used for analysis of total IgE level.

\section{Total IgE serum level analysis by ELISA}

A commercial human sandwich ELISA Kit (EUROIMMUN, Germany; Cat No. EV 3840-9601 E) was used to measure serum total IgE levels, according to the manufacturer's instructions. A microtiter plate ELISA reader (Biotek, USA) was used to measure the absorbance of standards and samples at $450 \mathrm{~nm}$. The upper reference range for normal subjects of 10-15 years old was $199 \mathrm{lU} / \mathrm{ml}$, while the upper reference range for participants of $>16$ years old was $100 \mathrm{IU} / \mathrm{ml}$.

\section{Determination of TLR-4Asp299Gly SNP (rs4986790) by PCR-RFLP}

-PCR for the amplification of TLR-4 gene: The PCR was performed using a Phusion ${ }^{\mathrm{TM}}$ Blood
Direct Master Mix kit (pub no. MAN0012900 Thermo Scientific ${ }^{\mathrm{TM}}$, USA) which was designed to perform PCR directly from whole blood with no prior DNA extraction or sample preparation according to the manufacturer's instructions using primers for human TLR-4 gene: ${ }^{26}$ (forward primer 5'dAGCATACTTAGACTACTACCTCCAT 3'; Reverse primer: $5^{\prime}$-d GAGAGATTTGAGTTTCAAT GTGGG-3'. The following are the PCR cycling conditions in the thermal cycler (Biometra, Germany): Cell lysis at $98^{\circ} \mathrm{C}$ for 5 minutes, then 40 amplification cycles of denaturation, annealing, and extension (at $98^{\circ} \mathrm{C}$ for 5 minutes, $58^{\circ} \mathrm{C}$ for 30 seconds, and $72{ }^{\circ} \mathrm{C}$ for 30 seconds, respectively); finally, a final extension cycle at $72^{\circ} \mathrm{C}$ for 1 minute. ${ }^{27}$ After amplification, the PCR reaction product was centrifuged at $1000 \times \mathrm{g}$ for 3 minutes to collect the supernatant for analysis. Then, $10 \mu \mathrm{L}$ of PCR product and $5 \mu \mathrm{L}$ of O'GeneRuler Express DNA Ladder (100-1000 bp) were directly loaded directly in a $1.5 \%$ agarose gel (BioShop Canada Inc., Burlington, Ontario, Canada). The amplified DNA product was separated by electrophoresis and visualized under ultraviolet light by ethidium-bromide staining.

-Restriction fragment length polymorphism (RFLP): The Fast Digest Nco1 (Thermo Scientific ${ }^{\mathrm{TM}}$, USA) restriction enzyme kit (Nco1; Thermo Scientific ${ }^{\mathrm{TM}}$, USA) was used to treat the resulting PCR product of the TLR-4 gene (188bp) according to the manufacturer's instructions. Nco1 recognizes 5'-CCATGG sites and cleaves between the first and second nucleotides. The digested products were then loaded into a $2 \%$ agarose gel and analyzed by electrophoresis. The product was visualized on an Ultra-Violet Transilluminator (Syngene, Frederick, Maryland, USA) and interpreted as follows: The wild AA genotype of the TLR-4 gene was indicated by an uncut band at $188 \mathrm{bp}$, while the mutant GG genotype was indicated by bands at 168 and 20 bp. The heterozygous AG genotype was indicated by bands at $188,168 \mathrm{bp}$ and $20 \mathrm{bp}$.

\section{Statistical analysis}

Data were analyzed using the Statistical Package of Social Science (SPSS) for Windows (Standard version 20). The Shapiro-Wilk test was used to determine the normality of data. We described 
data using numbers and percentages (qualitative) or means and standard deviations (quantitative parametric). Comparisons were made using the Mann-Whitney $U$ and KruskalWallis tests (in quantitative non-parametric groups of data) and the Chi-square test for groups of qualitative types of data. Significance was set at $P<0.05$.

\section{Results}

This study included 70 non-allergic subjects in the control group and 70 patients in the $A C$ group. The mean age was $11.92 \pm 4.04$ years and $12.71 \pm 4.78$ years for the $A C$ and control groups, respectively. While the $A C$ group consisted of $64.3 \%$ males and $35.7 \%$ females, the control group included $61.4 \%$ males and $38.6 \%$ females. We found no significant differences between the two groups regarding age and gender.
The AC group showed a significant association ( $P=0.001$ ) with a family history of allergy, $68.6 \%$ of AC patients had a positive family history of allergy compared to $32.9 \%$ of the control group. There were higher levels of total serum IgE in the $A C$ group than the control group $(249.21 \pm 60.25 \mathrm{IU} / \mathrm{ml}$ vs. $168.53 \pm 37.64$ $\mathrm{IU} / \mathrm{ml} ; P \leq 0.001)$. With respect to residence and socioeconomic status, no significant differences between the $A C$ patients and controls were observed.

Homozygous wild-type AA was the most prevalent genotype in both groups, with a statistically significant lower expression in the AC group compared to the control group $160 \%$ vs. $80 \% ; P=0.001$ ). Also, the heterozygous AG genotype expression was significantly lower in the AC group than the control group (8.6\% vs. 12.9\%; $P=0.001$ ), but the mutant homozygous GG genotype was significantly higher (31.4\% vs. 7.1\%; $P=0.001$ ), Table 1 .

Table 1. Comparison between allergic conjunctivitis patients and the control subjects.

\begin{tabular}{lccc} 
& $\begin{array}{c}\text { AC Patients (N=70) } \\
\mathrm{N}(\%)\end{array}$ & $\begin{array}{c}\text { Controls (N=70) } \\
\mathrm{N}(\%)\end{array}$ & ${ }^{*} P$ value \\
\hline Age (Years) & $11.92 \pm 4.04$ & $12.71 \pm 4.78$ & $\mathrm{NS}$ \\
\hline Gender & & & \\
Male & $45(64.3 \%)$ & $43(61.4 \%)$ & $\mathrm{NS}$ \\
Female & $25(35.7 \%)$ & $27(38.6 \%)$ & $\mathrm{NS}$ \\
\hline Residence & & & \\
Urban & $39(55.7 \%)$ & $48(68.6 \%)$ & \\
Rural & $31(44.3 \%)$ & $22(31.4 \%)$ & $\mathrm{NS}$ \\
\hline Socioeconomical & & $28(40 \%)$ & \\
Student & $32(45.7 \%)$ & $7(10 \%)$ & \\
Unemployed & $3(4.3 \%)$ & $9(12.9 \%)$ & \\
Housewife & $11(15.7 \%)$ & $13(18.6 \%)$ & \\
Office Worker & $10(14.3 \%)$ & $5(7.1 \%)$ & \\
Agricultural Workers & $11(15.7 \%)$ & $8(11.4 \%)$ & \\
Educationist & $3(4.3 \%)$ & $23(32.9 \%)$ & \\
\hline Family History Of Allergy & $48(68.6 \%)$ & $168.53 \pm 37.64$ & \\
\hline Total IgE (IU/ml) & $249.21 \pm 60.25$ & $56(80 \%)$ & \\
\hline TLR-4 Genotype & $42(60 \%)$ & $9(12.9 \%)$ & $(7.1 \%)$ \\
AA & $6(8.6 \%)$ & & \\
AG & $22(31.4 \%)$ & &
\end{tabular}


Of the AC patients, $55.7 \%$ were PAC type and $51.4 \%$ had a history of rhinitis. The most frequently reported symptoms were itching (100\%), tearing (85.7\%), and redness (82.9\%).
Regarding severity, $50 \%$ showed persistent moderate severity, $31.4 \%$ had persistent mild disease, and only $18.6 \%$ were severely persistent, Table 2.

Table 2. Characteristics of the allergic conjunctivitis (AC) patients.

\begin{tabular}{lcc}
\hline & AC PATIENTS & $\%$ \\
\hline Type of allergy & 31 & $44.3 \%$ \\
SAC & 39 & $55.7 \%$ \\
PAC & & \\
\hline Associated allergy (\%) & 36 & $51.4 \%$ \\
Rhinitis & 21 & $30 \%$ \\
Asthma & 16 & $22.9 \%$ \\
Urticaria & 11 & $15.7 \%$ \\
None & & \\
\hline Symptoms & 70 & $100 \%$ \\
Itching & 58 & $82.9 \%$ \\
Redness & 60 & $85.7 \%$ \\
Tearing & 44 & $62.9 \%$ \\
Foreign body sensation & 29 & $41.4 \%$ \\
Eyelid edema & 37 & $52.9 \%$ \\
Ocular dryness & 28 & $40 \%$ \\
Blurred vision & 13 & $18.6 \%$ \\
Photophobia & & \\
\hline Severity score & 22 & $31.4 \%$ \\
Mild persistent & 35 & $50 \%$ \\
Moderate persistent & 13 & $18.6 \%$ \\
Severe persistent & & \\
\hline PAC: Perennial Allergic Conjunctivitis; SAC: Seasonal Allergic Conjunctivitis &
\end{tabular}

AC patients with different disease severity showed significant differences in the skin prick test $(P \leq 0.001)$. The most frequently positive skin tests $(58.6 \%)$ were attributed to mixed pollen in all $A C$ patients. Positive skin tests were due to mixed grass (50\%) and mites (45.5\%) in mild AC cases. In the moderate AC group, mixed pollens (68.6\%) and mites (60.0\%) were the most common associated allergens. Severe AC patients showed reactions to mixed pollen (76.9\%), molds (23.1\%), pigeon feathers (23.1\%), and cotton (23.1\%) as determined by skin tests, Table 3. 
Table 3. Comparison of the skin prick test reactions according to allergic conjunctivitis severity.

\begin{tabular}{|c|c|c|c|c|c|c|c|c|c|}
\hline & \multicolumn{2}{|c|}{ Total $(\mathrm{N}=70)$} & \multicolumn{2}{|c|}{ Mild(N=22) } & \multicolumn{2}{|c|}{ Moderate $(\mathrm{N}=35)$} & \multicolumn{2}{|c|}{ Severe(N=13) } & \multirow{2}{*}{${ }^{*} P$ value } \\
\hline & $\mathrm{N}$ & $\%$ & $\mathrm{~N}$ & $\%$ & $\mathrm{~N}$ & $\%$ & $\mathrm{~N}$ & $\%$ & \\
\hline \multicolumn{10}{|l|}{ Skin prick test } \\
\hline Mixed pollens & 41 & $58.6 \%$ & 7 & $31.8 \%$ & 24 & $68.6 \%$ & 10 & $76.9 \%$ & \multirow{9}{*}{$\leq 0.001$} \\
\hline Mixed grass & 27 & $38.6 \%$ & 11 & $50 \%$ & 16 & $45.7 \%$ & 0 & -- & \\
\hline Molds & 19 & $27.1 \%$ & 4 & $18.2 \%$ & 12 & $34.3 \%$ & 3 & $23.1 \%$ & \\
\hline Wool & 12 & $17.1 \%$ & 8 & $36.4 \%$ & 4 & $11.4 \%$ & 0 & -- & \\
\hline House dust mites & 31 & $44.3 \%$ & 10 & $45.5 \%$ & 21 & $60 \%$ & 0 & -- & \\
\hline Cat hair & 4 & $5.7 \%$ & 4 & $18.2 \%$ & 0 & -- & 0 & -- & \\
\hline Pigeon feather & 11 & $15.7 \%$ & 4 & $18.2 \%$ & 4 & $11.4 \%$ & 3 & $23.1 \%$ & \\
\hline Cotton & 7 & $10 \%$ & 0 & -- & 4 & $11.4 \%$ & 3 & $23.1 \%$ & \\
\hline Cockroach & 11 & $15.7 \%$ & 4 & $18.2 \%$ & 7 & $20 \%$ & 0 & -- & \\
\hline
\end{tabular}

TLR-4 genotype expression was significantly different $(P=0.049)$ between severity groups of AC patients. While the wild AA genotype was the most prevalent in mild AC patients (68.2\%), the homozygous mutant GG genotype was more prevalent in severe patients $(53.8 \%)$. The AG genotype was only found in moderate $A C$ patients (17.1\%), Table 4 \& Figure 1.

Table 4. TLR-4 genotypes according to the severity of allergic conjunctivitis.

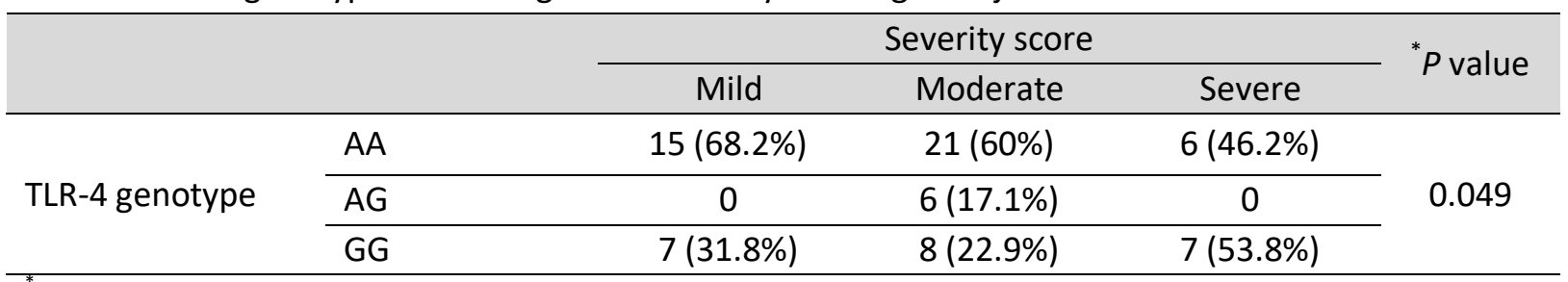

$P$ value $<0.05$ is statistically significant.

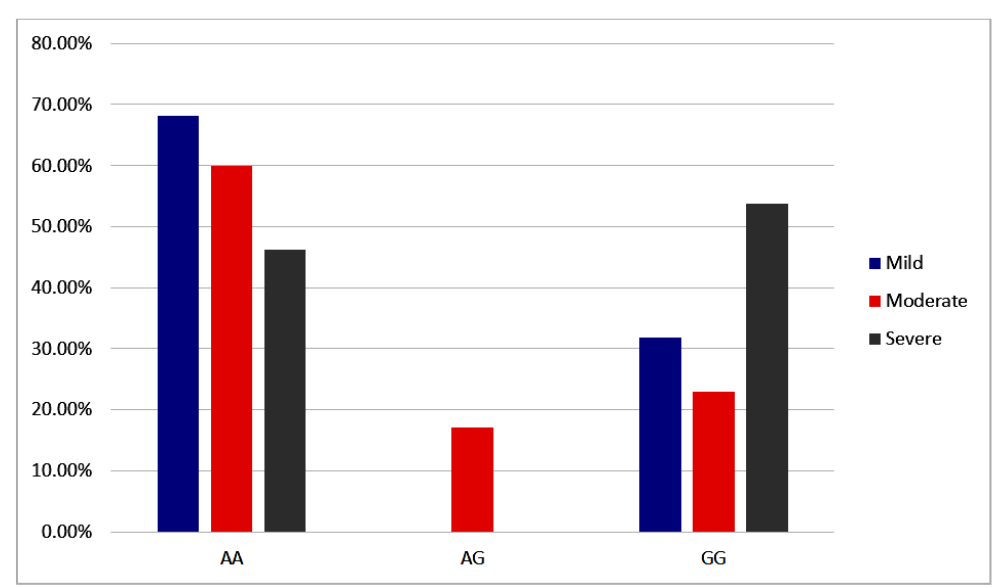

Figure 1. The frequency of the various TLR-4 genotypes according to the severity of allergic conjunctivitis $(P=0.049)$. The wild AA genotype was the most prevalent among the mild AC patients $(68.2 \%)$, whereas the homozygous mutant GG genotype was more prevalent in severe patients (53.8\%). The heterozygous AG genotype was only found in moderate AC patients (17.1\%). 
In terms of $\mathrm{AC}$ types, there was a significant gender difference between the PAC and SAC groups of patients, with males being more significantly affected by PAC (53.8\%; $P=0.041)$, while $77.4 \%$ of females by SAC. Residents of urban areas were more significantly affected by PAC (74.4\%; $P \leq 0.001)$, while those in rural regions were more affected by SAC (67.7\%). Subjects presented with PAC showed a significantly higher association with a family history of allergy (84.6\%; $P=0.001)$, lower levels of total serum IgE $(222.05 \pm 42.01 \mathrm{IU} / \mathrm{ml} \mathrm{IU} / \mathrm{ml} ; P$ $\leq$ 0.001), and higher moderate persistent severity (71.8\%; $P \leq 0.001)$. Such association was not observed for SAC patients. However, severe persistent cases were only found in $41.9 \%$ of the SAC group of patients. With regard to the TLR-4 genotype, the wild AA genotype was the most prevalent in both PAC and SAC groups, $46.2 \%$ and $77.4 \%$, respectively, Table 5 .

Table 5. Comparison of the characteristics of allergic conjunctivitis patients according to the type of allergy (PAC and SAC).

\begin{tabular}{|c|c|c|c|}
\hline & $\begin{array}{c}\text { PAC patients }(\mathrm{N}=39) \\
\mathrm{N}(\%)\end{array}$ & $\begin{array}{c}\text { SAC patients }(\mathrm{N}=31) \\
\mathrm{N}(\%)\end{array}$ & ${ }^{*} P$ value \\
\hline Age (years) mean \pm SD & $11.69 \pm 3.67$ & $12.21 \pm 4.51$ & NS \\
\hline \multicolumn{4}{|l|}{ Gender } \\
\hline Male & $21(53.8 \%)$ & $24(22.6 \%)$ & \multirow{2}{*}{0.041} \\
\hline Female & $18(46.2 \%)$ & 7 (77.4\%) & \\
\hline \multicolumn{4}{|l|}{ Residence } \\
\hline Urban & $29(74.4 \%)$ & $10(32.3 \%)$ & \multirow{2}{*}{$\leq 0.001$} \\
\hline Rural & $10(25.6 \%)$ & $21(67.7 \%)$ & \\
\hline \multicolumn{4}{|l|}{ Socioeconomical } \\
\hline Student & $16(41 \%)$ & $16(51.6 \%)$ & \multirow{6}{*}{0.002} \\
\hline Unemployed & $3(7.7 \%)$ & 0 & \\
\hline Housewife & $11(28.2 \%)$ & 0 & \\
\hline Office Worker & $6(15.4 \%)$ & $4(12.9 \%)$ & \\
\hline Agricultural Workers & $3(7.7 \%)$ & $8(25.8 \%)$ & \\
\hline Educationist & 0 & $3(9.7 \%)$ & \\
\hline Positive Family History Allergy & $33(84.6 \%)$ & $15(48.4 \%)$ & 0.001 \\
\hline Total IgE (UI/ml) Mean „SD & $222.05 \pm 42.01$ & $283.39 \pm 62.83$ & $\leq 0.001$ \\
\hline \multicolumn{4}{|l|}{ Severity Score } \\
\hline Mild Persistent & $11(28.2 \%)$ & $11(35.5 \%)$ & \multirow{3}{*}{$\leq 0.001$} \\
\hline Moderate Persistent & $28(71.8 \%)$ & $7(22.6 \%)$ & \\
\hline Severe Persistent & 0 & $13(41.9 \%)$ & \\
\hline \multicolumn{4}{|l|}{ TLR-4 Genotype } \\
\hline $\mathrm{AA}$ & $18(46.2 \%)$ & 24 (77.4\%) & \multirow{3}{*}{0.011} \\
\hline$A G$ & $6(15.4 \%)$ & 0 & \\
\hline GG & $15(38.5 \%)$ & $7(22.6 \%)$ & \\
\hline
\end{tabular}

When comparing the characteristics of $A C$ patients based on their TLR-4 genotype, no significant differences were observed in terms of age, gender, residence location, or family history of allergies. Only total serum IgE levels were significantly higher in homozygous mutant GG patients (274.55 $69.13 \mathrm{IU} / \mathrm{ml} ; P=0.004)$ than in homozygous wild-type AA (245.12 \pm $51.89 \mathrm{IU} / \mathrm{ml}$ ) and heterozygous $A G$ patients (215.7 83.3 IU/ml), Table 6. 
Table 6. Comparison of the characteristics of allergic conjunctivitis patients according to the TLR-4 genotype.

\begin{tabular}{|c|c|c|c|c|}
\hline & $\begin{array}{c}\text { AA patients }(\mathrm{N}=98) \\
\mathrm{N}(\%)\end{array}$ & $\begin{array}{l}\text { AG patients } \\
\qquad \begin{array}{c}(\mathrm{N}=15) \\
\mathrm{N}(\%)\end{array}\end{array}$ & $\begin{array}{l}\text { GG patients } \\
\qquad \begin{array}{c}(N=27) \\
N(\%)\end{array}\end{array}$ & ${ }^{*} P$-value \\
\hline Age (years) mean $\pm S D$ & $11.15 \pm 3.31$ & $13.25 \pm 2.46$ & $13.02 \pm 5.27$ & NS \\
\hline \multicolumn{5}{|l|}{ Gender } \\
\hline Male & $63(64.3 \%)$ & $9(60 \%)$ & $16(59.3 \%)$ & \multirow{2}{*}{ NS } \\
\hline Female & $35(35.7 \%)$ & $6(40 \%)$ & $11(40.7 \%)$ & \\
\hline \multicolumn{5}{|l|}{ Residence } \\
\hline Urban & $61(62.2 \%)$ & $10(66.7 \%)$ & $17(63 \%)$ & \multirow{2}{*}{ NS } \\
\hline Rural & $37(37.8 \%)$ & $5(33.3 \%)$ & $10(37 \%)$ & \\
\hline \multicolumn{5}{|l|}{ Socioeconomical } \\
\hline Student & $41(41.8 \%)$ & $6(40 \%)$ & $13(48.1 \%)$ & \multirow{6}{*}{ NS } \\
\hline Unemployed & $7(7.1 \%)$ & $2(13.3 \%)$ & $1(3.7 \%)$ & \\
\hline Housewife & $14(14.3 \%)$ & $2(13.3 \%)$ & $4(14.8 \%)$ & \\
\hline Office worker & $16(16.3 \%)$ & $2(13.3 \%)$ & $5(18.5 \%)$ & \\
\hline Agricultural workers & $13(13.3 \%)$ & $1(6.7 \%)$ & $2(7.4 \%)$ & \\
\hline Educationist & $7(7.1 \%)$ & $2(13.3 \%)$ & $2(7.4 \%)$ & \\
\hline Family history of allergy & $50(51 \%)$ & $7(46.7 \%)$ & $13(48.1 \%)$ & NS \\
\hline Total IgE (IU/ml) mean \pm SD & $245.12 \pm 51.89$ & $215.8 \pm 43.35$ & $274.55 \pm 69.13$ & 0.004 \\
\hline
\end{tabular}

\section{Discussion}

$A C$ is a prevalent hypersensitivity disorder affecting up to $40 \%$ of the population worldwide. Itching, redness, and swelling are common symptoms which have a substantial impact on patients' quality of life. According to the duration of allergen exposure, $\mathrm{OA}$ is classified into seasonal and perennial forms. The seasonal form is based on the seasonal presence of a specific aeroallergen, while the perennial form is based on continual exposure to an allergen such as house dust or pet dander. ${ }^{28}$ The current study was conducted on $70 \mathrm{AC}$ patients and 70 non-allergic control subjects with the aim of investigating the association between the TLR-4 (Asp299Gly) gene polymorphism and patients' susceptibility to AC.

In the present study, the AC group comprised $64.3 \%$ males and $35.7 \%$ females and showed a significant association with family history of allergy (68.6\%). Similarly, Haggag et al., 2017, reported male predominance (53.1\%), and a significant association with positive family history (62.5\%) in their included AC patients. They also found that $25 \%$ of cases were presented with AC alone, while $31.3 \%$ had associated AR (rhino-conjunctivitis), and $21.9 \%$ presented with an allergy triad, which means that rhino-conjunctivitis are associated with asthma. ${ }^{29}$ 
Furthermore, Oliveira et al., 2007, observed that $50 \%$ of their study subjects demonstrated a positive family history of atopy and $75 \%$ of cases had other atopic associated disorders, with AR (70\%) and asthma (35\%) being the most predominant ones. ${ }^{30}$ In addition, in a study by Arej et al., 2018, the majority of AC cases lived in cities $(72.7 \%)$ and $29.5 \%$ of them were students. Associated allergies (rhinitis, asthma or urticaria) were found in more than $70 \%$ of $A C$ patients included in their study. ${ }^{4}$

In our study, mixed grass (50\%) and mites $(45.5 \%)$ were the most common allergens linked to positive skin tests in mild AC patients. On the contrary, in the moderate AC group, mixed pollens $(68.6 \%)$ and mites $(60 \%)$ were the most common related allergens. Skin testing in severe AC patients only reacted to mixed pollens $(76.9 \%)$, molds $(23.1 \%)$, pigeon feathers (23.1\%), and cotton (23.1\%). This is in line with the findings of Rasheed et al., 2015, who reported that the most prevalent offending allergens were Bermuda grass pollens, followed by animal dander, mites, and molds. ${ }^{30}$ Also, according to Haggag et al., 2017, the most common allergens that resulted in a positive skin prick test were house dust mites, mold, and cockroaches $(96.9 \%)$, followed by grass pollen $(87.5 \%) .^{29}$

Pruritus is the most prevalent symptom of $A C$, and its severity can range from moderate to highly debilitating. Besides, it can be painful in rare cases. Tearing, redness, a gritty sensation, mucous discharge, and swelling of the eyelids are some of the other symptoms. ${ }^{31}$ The symptoms are typically bilateral and linked to rhinitis. In severe cases, blurred vision and photophobia were recorded. ${ }^{32}$ Likewise, the most frequently reported symptoms of $\mathrm{AC}$ patients in our study were itching $(100 \%)$, tearing (85.7\%), and redness (82.9\%).

In our study, $55.7 \%$ of $A C$ patients were of the PAC type, $51.4 \%$ had a history of rhinitis, and $50 \%$ with moderate persistent severity. Our AC patients had higher levels of total serum IgE $(249.21 \pm 60.25 \mathrm{lU} / \mathrm{ml})$ compared to the control group $(168.53 \pm 37.64 \mathrm{IU} / \mathrm{ml} ; \quad P \leq 0.001)$. Moreover, there was a significant difference between SAC and PAC patients as it was significantly lower in the PAC group (222.05 \pm
$42.01 \mathrm{lU} / \mathrm{ml})$ than SAC group $(283.39 \pm 62.83$ $\mathrm{IU} / \mathrm{ml} ; P \leq 0.001)$. This is partially similar to a study by Gurses et al., 2009, in which $32 \%$ of the included AC patients were diagnosed as PAC, and $68 \%$ diagnosed as SAC. The mean levels of total serum IgE of their controls and AC patients were $36.36 \mathrm{IU} / \mathrm{ml}$ and $227.40 \mathrm{IU} / \mathrm{ml}$, respectively. ${ }^{33}$ Furthermore, Arej et al., 2018, found a four-time predominance of SAC (80\%) over PAC (20\%; $P=0.002)$ in their study patients, and significantly higher levels of total serum IgE. ${ }^{4}$ Mimura et al., 2011, demonstrated that the high total serum IgE levels were correlated with the total tear IgE score and specific serum IgE levels in OA patients. ${ }^{34}$

Increased cytokine synthesis after TLR stimulation can lead to inflammation and allergies. Involvement of innate immunity, specifically TLRs, induces diversity in the mechanism of genesis and clinical manifestations of allergic reactions, particularly in IgE-independent variation. ${ }^{35}$ Consequently, SNPs in the TLR-4 gene may be linked to atopic disorders. $^{33}$ TLR-4 (Asp299Gly) has been identified in humans and was found to be associated with hypo-responsiveness to inhaled allergens. ${ }^{19}$

In 2013, Levchenko et al., investigated the frequencies of several TLR gene SNPs, including the TLR-4 896A/G SNP in children with atopic dermatitis (AD) against controls. They found that the TLR-4 gene's mutant 896G allele was more frequently associated with $A D$ in children who were susceptible to acute respiratory viral infections (ARVIs) compared to the control group $(P=0.038)$. In the control group, the frequencies of TLR-4 genotypes were $96.3 \%$, $3.7 \%$ and $0.0 \%$ for the wild-type $A A$, the heterozygous $A G$ and the mutant $G G$ genotypes, respectively. While in $A D$ children who were predisposed to frequent ARVIs, their frequencies were $85.19 \%, 11.11 \%$ and $3.7 \%$, respectively. ${ }^{36}$

In contrast, Böttcher et al., 2004, who studied the TLR4 (Asp299Gly) SNPs in the presence of asthma and ARC in children, revealed that the frequencies of the wild $A A$ and the heterozygous AG genotypes in children with asthma were $23 \%$ and $55 \%$, respectively $(P=0.03)$, while their frequencies in children 
with rhino-conjunctivitis were $22 \%$ and $36 \%$, respectively $(P>0.05)$. They also found that TLR-4 (Asp299Gly) SNP was only among children with atopic asthma and not with ARC. ${ }^{37}$ On the contrary, a previous study by Raby et al., 2002 which included a heterogeneous North American and Canadian cohort, showed no association between genetic variation in the TLR-4 gene and asthma susceptibility. ${ }^{38}$

The TLR-4 SNP was not associated with positive SPT or atopic illnesses other than asthma. However, Böttcher et al., 2004, reported that the TLR-4 SNP was only present in asthmatic children who were SPT-positive, indicating that the TLR-4 SNP may be linked to atopic children's vulnerability to asthma but not associated with the development of atopic reactivity and IgE production and reinforcing mechanistic ideas based on immune cell polarization. Consequently, the alternative TLR4 activated pathways could be involved in the development of atopic asthma. ${ }^{37}$ TLR-4 expression was low in the human airway epithelium of people with the Asp299Gly mutation, suggesting that the SNP had local consequences in the airways, ${ }^{19}$ and the TLR-4 Asp299Gly variant was linked to a higher incidence of infections that lead to the development of atopic diseases. ${ }^{39}$ Previous research has found a correlation between environmental variables and AR when TLR-4 SNPs are considered. However, no evidence was found to demonstrate that SNPs in TLR genes contribute to the development and prognosis of AR and ARC. ${ }^{40}$

Based on the current study findings, we may conclude that TLR-4 (Asp299Gly) SNP may be associated with $A C$ in which homozygous mutant GG genotype presence has higher odds of severe course. Specific sensitization, in combination with genetic SNPs in innate immunity pathways, could act as triggers for AC.

\section{Author Contributions}

$S A B$ and SIT; performed the laboratory work. DES, AIAA and SHF; made the statistical analysis. MAH; examined the patients. SAB, DES, SHF and MAH; collected samples. All authors participated in writing and reviewing the paper.

\section{Declaration of Conflicting Interests}

The author(s) declared no potential conflicts of interest with respect to the research, authorship, and/or publication of this article.

\section{Funding}

The author(s) denies receipt of any financial support for the research, authorship, and/or publication of this article.

\section{Ethical approval}

The study protocol was reviewed and approved by the Institutional Review Board (IRB) (approval no. 6877-13-12-2020) at Zagazig University.

\section{Informed consent}

At the time of recruitment, all subjects (or guardians of children, less than 18 years of age) signed an informed written consent.

\section{References}

1. Leonardi, A., Doan, S., Fauquert, JL., et al. (2017). Diagnostic tools in ocular allergy. Allergy, 72(10):1485-1498. doi: 10.1111/all.13178.

2. Sánchez-Hernández, MC., Montero, J., Rondon, C., et al. (2015). Consensus document on allergic conjunctivitis (DECA). Journal of Investigational Allergology and Clinical Immunology, 25(2):94106.

3. Dupuis, P., Prokopich, C., Hynes, A., et al. (2020). Contemporary look at allergic conjunctivitis. Allergy, Asthma \& Clinical Immunology.16:5. doi: 10.1186/s13223-020-0403-9.

4. Arej, N., Irani, C., Abdelmassih, Y., et al. (2018). Evaluation of allergic sensitization in Lebanese patients with allergic conjunctivitis. International Ophthalmology. 38(5):2041-2051. doi: 10.1007/s10792-017-0696-y.

5. Bielory, L., Meltzer, EO., Nichols, KK., et al. (2013). An algorithm for the management of allergic conjunctivitis. Allergy \& Asthma Proceedings. 34(5):408-20. doi: 10.2500/aap.2013.34.3695.

6. Wu, MM., Yau, GS., Lee, JW., et al. (2014). Retrospective review on the use of topical cyclosporin a $0.05 \%$ for paediatric allergic conjunctivitis in Hong Kong Chinese. Scientific World Journal. 396987. doi: 10.1155/2014/ 396987. 
7. Bernstein, IL., Li, JT,, Bernstein, DI., et al. (2008). Allergy diagnostic testing: An updated practice parameter. Annals of Allergy, Asthma \& Immunology. 100 (3 Suppl 3): S1-148. doi: 10.1016/s1081-1206(10)60305-5.

8. Nie, L., Cai, S.-Y., Shao, J.-Z, et al. (2018). Toll-Like Receptors, Associated Biological Roles, and Signaling Networks in Non-Mammals. Frontiers in Immunology, 9. doi: 10.3389/fimmu.2018.01523.

9. von Mutius E. (2001). Infection: friend or foe in the development of atopy and asthma? The epidemiological evidence. The European respiratory journal. 18(5), 872-881. https://doi.org/10.1183/09031936.01.00268401

10. Redfern, R. L., \& McDermott, A. M. (2010). Tolllike receptors in ocular surface disease. Experimental eye research, 90(6), 679-687. https://doi.org/10.1016/j.exer.2010.03.012

11. Bonini, S., Micera, A., lovieno, A., Lambiase, A., \& Bonini, S. (2005). Expression of Toll-like receptors in healthy and allergic conjunctiva. Ophthalmology, 112(9), 1528-1549. https://doi.org/10.1016/j.ophtha.2005.04.009

12. Nilsson, D., Andiappan, AK., Halldén,. C, et al. (2012). Toll-like receptor gene polymorphisms are associated with allergic rhinitis: a case control study. BMC Medical Genetics.13:66. doi: 10.1186/1471-2350-13-66.

13. Georgel, P., Macquin, C. and Bahram, S. (2009). The Heterogeneous Allelic Repertoire of Human Toll-Like Receptor (TLR) Genes. PLoS ONE, 4(11), p.e7803. doi: 10.1371/journal.pone.0007803.

14. Matsumoto, K., Kouzaki, H., Yamamoto, S., et al. (2020). In vitro and in vivo inhibitory effects of TLR-4 agonist, glucopyranosyl lipid A (GLA), on allergic rhinitis caused by Japanese cedar pollen. Allergy.; 75(2):446-449. doi: 10.1111/all.13989.

15. Shastry, B.S. (2002). SNP alleles in human disease and evolution. J Hum Genet. 47(11):561-6. doi: $10.1007 / \mathrm{s} 100380200086$.

16. Lee, E., Lee, S., Park, MJ., et al. (2021). Interaction of the TLR-4 rs1927911 polymorphism with house dust mite sensitization in allergic rhinitis with its prognosis. Asian Pacific Journal of Allergy and Immunology. doi: 10.12932/AP-170820-0943. Online ahead of print.

17. Medvedev A. E. (2013). Toll-like receptor polymorphisms, inflammatory and infectious diseases, allergies, and cancer. Journal of interferon \& cytokine research: the official journal of the International Society for Interferon and Cytokine Research, 33(9), 467-484. https://doi.org/10.1089/jir.2012.0140
18. Gao, Z., Rennie, D. C., Senthilselvan, A. (2010). Allergic rhinitis and genetic components: focus on Toll-like receptors (TLRs) gene polymorphism. The application of clinical genetics, 3, 109-120. https://doi.org/10.2147/TACG.S8380

19. Arbour, N. C., Lorenz, E., Schutte, B. C., et al. (2000). TLR-4 mutations are associated with endotoxin hypo-responsiveness in humans. Nature genetics. 25(2):187-91. doi: 10.1038/76048.

20. Yang, I. A., Barton, S. J., Rorke, S., et al. (2004). Toll-like receptor 4 polymorphism and severity of atopy in asthmatics. Genes and immunity, 5(1), 41-45. https://doi.org/10.1038/sj.gene.6364037

21. Jung, Y. H., Seo, J. H., Kim, H. Y., et al. (2015). The relationship between asthma and bronchiolitis is modified by TLR4, CD14, and IL-13 polymorphisms. Pediatric pulmonology, 50(1), 816. https://doi.org/10.1002/ppul.22978

22. Sahin, F., Yıldız, P., Kuskucu, A., et al. (2014). The effect of CD14 and TLR4 gene polymorphisms on asthma phenotypes in adult Turkish asthma patients: a genetic study. BMC pulmonary medicine, 14, 20. https://doi.org/10.1186/14712466-14-20

23. Gotua, M., Gamkrelidze, A., Rukhadze, M., et al. (2019). 2020 Aria Care Pathways For Allergic Rhinitis - Georgia. Georgian medical news, (297), 108-117.

24. Heinzerling, L., Mari, A., Bergmann, KC., et al.( 2013). The skin prick test - European standards. Clinical and translational allergy.3(1):3. doi: 10.1186/2045-7022-3-3.

25. Fleischer, D. M., Chan, E. S., Venter, C., et al. (2021). A Consensus Approach to the Primary Prevention of Food Allergy Through Nutrition: Guidance from the American Academy of Allergy, Asthma, and Immunology; American College of Allergy, Asthma, and Immunology; and the Canadian Society for Allergy and Clinical Immunology. The journal of allergy and clinical immunology. In practice, 9(1), 22-43.e4. https://doi.org/10.1016/j.jaip.2020.11.002

26. El Sayed, R., Arafa, R., El-Mosallamy, W., et al. (2015). Polymorphism of Toll like Receptors $2 \& 4$ Genes and the Risk of Bronchial Asthma. Egyptian Journal of Medical Microbiology, 24(4), 129-134.

27. Hammad, NM., El Badawy, NE., Nasr, AM., et al. (2018). Mannose-binding lectin gene polymorphism and its association with susceptibility to recurrent vulvovaginal candidiasis. BioMed Research International. 7648152. doi: 10.1155/2018/7648152. 
28. Bielory, L., Delgado, L., Katelaris, CH., et al. (2020) ICON: Diagnosis and management of allergic conjunctivitis. Annals of Allergy, Asthma \& Immunology. 124(2):118-134. doi: 10.1016/j.anai. 2019.11.014.

29. Haggag, MG., Aboelazm, AA., Al-Gazzar, AM., et al. (2017). Immunoblotting technique versus skin prick test for detection of allergen specific immunoglobulin e in allergic Conjunctivitis. Journal of Ophthalmology and Related Sciences. 1(2):39-50.

30. Rasheed, SM., Khudhair, SA., AL-Fatlawi, SN., (2015). Results of serum specific IgE (sslgE) allergy test in adult patients suffering from respiratory allergy in Al-Najaf City. www.med.uokufa.edu.

31. La Rosa, M., Lionetti, E., Reibaldi, M., et al. (2013). Allergic conjunctivitis: a comprehensive review of the literature. Italian journal of pediatrics, 39, 18. https://doi.org/10.1186/18247288-39-18

32. Oliveira, LA., Mallozi, MC., Sole, D., et al. (2007). Are cutaneous hypersensitivity tests to inhalant allergens a severity marker for vernal keratoconjunctivitis? Arquivos Brasileiros de Oftalmologia. ;70(6):991-5. doi: 10.1590/s000427492007000600020.

33. Gurses, O., Taheri, N., (2009). Serum IgE Levels in Patients with Allergic Conjunctivitis and Contact Lens Wearers. Investigative Ophthalmology \& Visual Science. 50(13):6321.

34. Mimura, T., Usui, T., Mori, M., et al. (2011). Relation between total tear IgE and specific serum IgE in seasonal allergic conjunctivitis.
Cornea. 30(7):790-5. doi: 10.1097/ICO.0b013e $3182000 f e b$.

35. Zakeri, A., Russo, M., (2018). Dual Role of Toll-like Receptors in Human and Experimental Asthma Models. Frontiers in Immunology. 9: 1027. doi: 10.3389/fimmu.01027.

36. Levchenko, LY., Izmailova, OV., Shlykova, OA., et al. (2013). TLR4 896A/G Gene Polymorphism, Rather Than the TLR4 1196C/T and TLR2 2258G/A Gene Polymorphisms, Determines the Severe and Aggravated Course of Atopic Dermatitis in Children. TSitologiia i genetika. 47(3):46-53.

37. Böttcher, MF., Hmani-Aifa, M., Lindström, A., et al. (2004). A TLR4 polymorphism is associated with asthma and reduced lipopolysaccharideinduced interleukin-12(p70) responses in Swedish children. The Journal of Allergy and Clinical Immunology.; 114(3):561-7. doi: 10.1016/j.jaci.2004.04.050.

38. Raby, BA., Klimecki,WT., Laprise, C., et al. (2002). Polymorphism in toll-like receptor 4 are not associated with asthma or atopy-related phenotypes. American Journal of Respiratory and Critical Care Medicine; 166:1449-56. doi: 10.1164/rccm.200207-6340C.

39. Lorenz, E., Mira, JP., Frees, LK., et al. (2002). Relevance of mutations in the TLR4 receptor in patients with gram negative septic shock. Archives of internal medicine. 162:1028-32. doi: 10.1001/archinte.162.9.1028.

40. Seo, JH., Kim, HY., Jung, YH., et al. (2015). Interactions between innate immunity genes and early-life risk factors in allergic rhinitis. Allergy, Asthma \& Immunology Research. 7(3):241-8. doi: 10.4168/aair.2015.7.3.241. 